\title{
С.А. Владимиров
}

\section{О ЦЕЛОСТНОЙ СБАЛАНСИРОВАННОЙ ТЕОРЕТ ЧЕСКИ И РЕАЛЬНО ВОЗМОЖНОЙ МОДЕЛИ УНИВЕРСАЛЬНОЙ МАКРОЭКОНСМИЧЕСКОЙ СИСТЕМЫ

\author{
S.A. Vladimirov
}

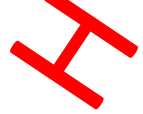

\section{A COMPREHENSIVE THEORETICALLY BALANCED AND PRACTICALLY ACHIEVABLE MODEL OF A UNIVERSAL MACROECONOMIC SYSTEM}

Численные показатели уровня и темпов экономического и социального развигия являются важнейшими для оценки эффективности проводтмой в стране экономической политиу., последующих ее изменений, управления общественным рагвитием в целом. Наиболее распростүдненная среди экономистов модель П. Самуэльсона выводит лкобы прямы овязи между большими объемами накоплений и соответствующим уровнем потребления, экономиче ґе законы возрастатия дополнительных затрат, убывающих эффективности и производительности/доходности, экономиу. на масштабе производства и др. Развитие современных развиғающихся и развитых экономик зачасгую противоречат этой модели экономического выбора. В прељложенной модели, близкой к интерпретации «эконофизического» направления в современной эко'юмической тө ии (циклу Карно в термодинамике), полученная экономической системой конкретндя сумма государ 1 В нных расходов и инвестиций всегда может привести в идеальном случае («нулевык потерь» максимальљ возможных общественных эффективностей государственных расходов и инв ‘стиций) к максимально возможному гемпу экономического роста. Результатом разработанной модели сбалансированной открытой экономики является преодоление барьера мнимого отсутствия в эко'юмической суютеме количественных констант, так разительно отличающих ее от физических систем (при полном с созна иии ее ограничений: несводимости общественного прогресса, развития человека к увеличению днех ыых доходов иля к приумножению материального богатства, темпов экономич'сского роста). Предложенная целостнгя макроэкономическая модель после внедрения ее в процесс погготовки, согласования, утверждения $v_{\star}$ анализа исполнения бюджета соответствующими государственн'лми органами позволит не вслепую научно обосновывать и жестко контролировать эффективность направлений экроэкономического ргзвития, отклонения их от идеальных.

ЭФФЕКГИВНОСТЬ; МАК ОЭКОНОМИКА; РАЗВИТИЕ; СТРАТЕГИЯ; СБАЛАНСИРОВАННОСТЬ; УСТОЙЧИ.ВОСТЬ; КАЧЕСТВО; ПОЛИТИКА; НАЛСГИ.

$\mathrm{N}$ 'merical indicators of the level and pace 'f economic and social development are essential for evaluating the eifectiveness of n country's economic pciicy, its subsequent changes, and overall management of social devilopment. The Sam elson model, most common among economists, establishes supposedly direct links $\mathrm{b}$,tween large amo nts f savings and the corresponding consumption level, the economic law of increasing ddditional cost, decreasing the efficiency and performance/yields, economies of scale, etc. The development of modern developing and developed economies often contradicts this model of economic choice. The author's model, which is close to the interpretation of the 'econophysical' direction in modern economic theory (the Carnot cycle in thermodynamics) implies that the specific amount of state expenditure and investments obtained by the economic syster s should ideally (in case of 'zero-losses' of the maximum possible public efficiencies of state spending ard investments) lead to the maximum possible rate of economic growth. The result of the balanced open ec'snomy model developed by the author is in overcoming the barrier of the alleged lack of quantitative constants, in an economic system, which makes it drastically different from physical systems (the author is fully aware of the system's limitations: the irreducibility of social progress and human development to increasing the incoms or augmenting material wealth, or economic growth rates). In our opinion, the comprehensive macroeconomic model proposed above should allow, following its introduction into the preparation, negotiation, approval and implementation of budget analysis by the corresponding government auihorities, to 'cons ciously', instead of blindly, scientifically substantiate and strictly control the efficiency of the directicns of macrueconomic development, and their deviation from the ideal.

EFFIC'ENC:; MACROECONOMICS; DEVELOPMENT; STRATEGY; BALANCE; SUSTAINABILITY; QUALITY; POLICY; TAXE'S. 
Пусть только наша идея будет правильной, и тогда, несмотря на наличие препятствий, стоящих на пути к ее осуществлению, она не будет невозможной [1, с. 129]."

Введение. Общественное развитие находит свое конкретное выражение в статистических (в том числе макроэкономических) показателях, без установления и измерения численных значений которых невозможно управление. Устойчивое развитие без разрушения в течение неограниченно длительного периода времени единой системы «природа - человек» не должно ставить под сомнение способность будущих поколений удовлетворять свои потребности. Такое развитие определs ется тремя переменными: эффективностью экономики, экологической стабильног,тью, социальной справедливостью [1, с. 59].

Показатели уровня и темпов эксномического и социального развития, в 'астности, показатели уровня жизни, являются важнейшими для оценки эффективностуі проводимой в стране экономической политтки и, в конечном счете, существующего в ней общественного строя. В то же время высокие темпы экономического развития не всегда яғля критерием соответствующего роста уров я жизни населения [9, с. 468]. В ходе подлинного экономического рлста происходит инновационное обновление производстмчного капитала страны, устагевшее оборуд вван е заменяется новым, с лучшими качестве ми характеристиками, так что степень износа основных фондов в целом по экономике, по меньшей мере, не увеличивается /3, 6].

Мет'дика и результоты исследования. Привегем критический анализ имеющихся в литегатуре, экономической и управленгеской прг.ктике подхопов к решению проблемы. Болєе шестидеся и лет в экономическсй науке и преподавании дм Аирует модель экономического выбора «экономиста всех рремен и всех народов» П. Самуэльсона [3; 4, с. 22]. Он утверждал, что язык математикч является единственно возможным для иэложения положений современной эконом!.ческой теории. Из этой модели выводятся лкобы прямая (жест-

\footnotetext{
* Идея совершеннгго, справедливо управляемого государства, гбалансированной открытой эффективной эконсмики. $-C . B$
}

кая) связь между большими объемами накоплений и соответстзующим уровнем потребления, экономические законы возрастания дополнительных затрат, убывающих эффективности и пгоизводительности/ доходности, экономии га масштабе производства и др. Развитие современных пазвивающихся и ра?витых эгономик зачаст. Противоречат этой модели. экономического в чбора.

Рэссмотрим далее общепринятую мэтематическую модель сбалансированной огккрытой эк.номики (CO5 и взаимосвязи между абсолютными знач иями основных макроэкономических показателей (МЭП): ілланируемой (прогнозируемой) госорганами величиной валового внутреннего продукт $\curvearrowleft$, государственными ходами, инвестициями, потреблением, нал овым бременем, сальдо платежного баланса страны и их ногмами, общественными эффективностями, темпом экономического роста сбалансироғанной открытой эконоүи, ставкой ссудного процента Центробанстраны и инфлгцией $[10$, с. 9].

Взаимозавис'ямость вышеуказанных важнейших макгоэкономических показателей можно предс гавить в математической и графической ґорме, см. рис. 1 и пояснения к формулам. (1)-(5).

Главное отличие нашей модели в том, что разделжемое большинством экономистов утверждение о прямой зависимости между объемгми накоплений и ростом потребления (где б’лььшие объемы накоплений неизбежно приводят к резкому повышению уровня потребления), вытекающее из модели П. Самуэльсона, заведомо неточно. Как показала мировая практика (в том числе в России 2001-2013 гг.), значительные объемы накоплений не всегда приводят к высокому приросту потребления, иногда вплоть до «проедания» накопленных стратегических резервов, что и находит отражение на представленном графике. При этом в соответствии с историческим опытом и культурными традициями средняя норма налогового бремени в макроэкономических системах не может снижаться ниже десяти процентов («библейская десятина», близкая, по нашему мнению, к анархии) [5, с. 44]. В то же время ни при каких обстоятельствах средняя налоговая нагрузка не может превышать своего максимального значения, отраженного на графике кривой $\theta_{s=0}^{\max }=g^{\max }=1 / \psi$. 


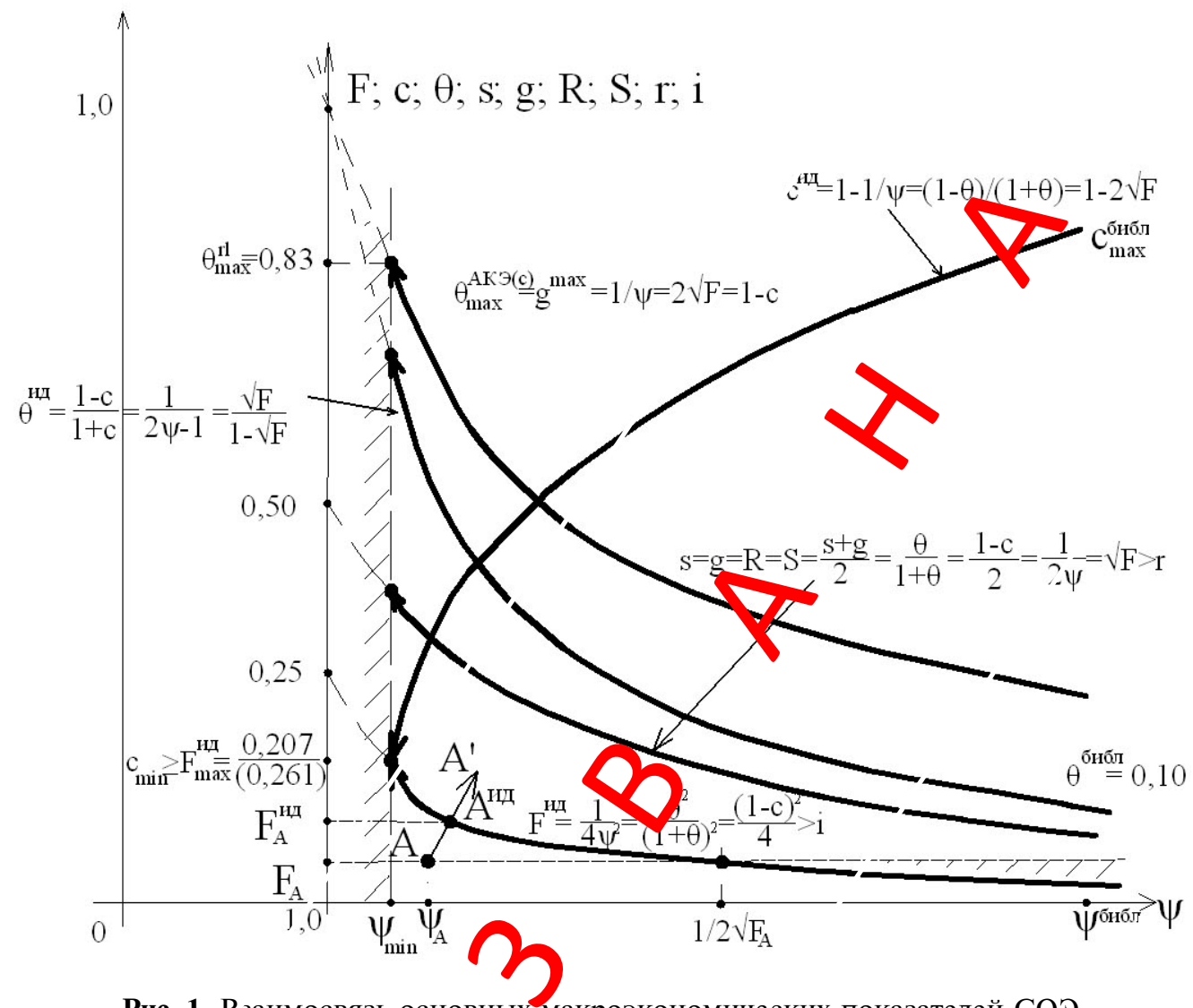

Рис. 1. Рзаимосвязь основных макроэкономических показателей СОЭ с нулевым сальдо платежногс баланса

Заштрихованғя области невозможных значений: меньших, чем $\psi_{\min }$, и больших, чем $\psi=1 / 2 \sqrt{ } F_{\mathrm{A}}$

Эта кривая слответствует а тмин истративно-командной экономике (системе) АКЭ(С) (например, СССР), в которой инвестиции (капитальнь'е вложения) являлись «перераспределенными» государ твенными расходами, поскольку государственная собственность бола абсллютно преобладающей (более 9 s \%) [8, c. 57]. Весьма показательно, что хагактер эточ̆ кривой позволяет сделать теорегически ксрректный вь вод, то в АКЭ(С) нет никаких ' снований заве омо идеологически ограничи-

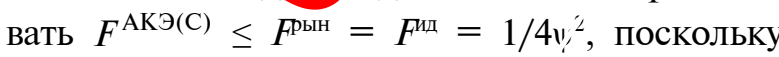
не форма собственности, а кагество организации и управления и перерәгпределения валового продукта - суть эк'лномического потенциала любого общества [12, с. 187].

Важно также иметь в виду, что средняя налоговая нагрузка в идеальной СОЭ для любых соотношений основных МЭП не минимальная, но имелно сбалансированная относительно соотвє теоретически в’эможному экономическому росгу показателей норм государственных расходов, инвестиций и их общественных эффективностей, одновременно равных корню квадратному из численного значения экономического роста [6, с. 30].

Бесконечное множество реальных состояний СОЭ располагается на площади ниже кривой максимально возможного темпа экономического роста: $F^{\text {ид }}=1 / 4 \psi^{2}$. Эти состояния определяются соответствующими точками, например на графике точкой $A$ с координатами: $A\left[\psi_{A} ; F_{A} ; \Omega_{A}\right]$. Из этой точки возможны следующие очевидные направления развития (повышения эффективности и качества) макросистемы:

а) идеальное (единственное, стратегическое) - кратчайшее направление к кривой максимально возможного темпа экономического роста (т. е. в направлении перпендикуляра $A \vec{A}$ к касательной из точки $A$ ). Более подробно: направление развития реальной экономики выбрано государственными орга- 
нами близким к идеальному (наилучшему теоретически возможному), если оно сопровождается повышением экономического роста при снижении суммы норм государственных расходов и инвестиций, а также и средней налоговой нагрузки при одновременном повышении нормы потребления (в том числе за счет положительного сальдо платежного баланса страны, вызванного, прежде всего, экспортом высокотехнологичной продукции) и сбалансированностью основных макроэкономических параметров [11, с. 128].

б) неидеальные - стремящиеся (близкие) к идеальному;

в) заведомо неэффективные для обществс. - такие направления развития реальной эк номики, которые сопровождаются снижением экономического роста и нормы потгебления при одновременном росте суммн, норм государственных расходов и инвесіиций и средней налоговой нагрузки, несбалансированностью всех или большей части основных макроэкономических параметргв - коррупционные или заведомо некомпетентные направления экономического развития: «на авось», вплоть до умышленного разваға деградация собственной эк'Јномки по Сор $\mathrm{rq}$ «экономических убийш" (общеизвестна пюблема «псевдоинвест'цций» западных инвесторов в предприятия российского высокотехнологичного комплекса, кот оре зачастую приводят к ликзидации этих пре приятий, например уничгожение конкурепюов, скупка земли под прєдприятиями и др.) [7, с. 26].

Достижение равновесия в реальной макроэкономической сист ме является труднейшей фиғансово-политичео ой задачей (в т’м числе погашение государственного дотга), вклю'ающей выпуск госзаймов, ужестсчение налэгообложения печатание денег. Пги этом нғсбалансиров нно ть экономическгй системы может быть объ ктивной (войн', периоды крупных социально-экономических реформ, катаклизмов), случайной и прэднамеренной, выгодной определенным «группам влияния» (как правило, властным или оппозиционным, в том числе теневым, структурам), но, безусловно, невыгодной общегтву в целом.

Несложный матемагический анализ соотношений между оснгвными МЭП при конкретной заданной государственными органами численной величине темпа экономиче- ского роста позволяет жестко выделить следующие «иерархические ряды (ИР) МЭП» с соответствующими диапазонами ограничений их «дрейфг» внутри конкретного ряда.

\section{І. Равнов ссные СОЭ}

1. Идеальные ИР СОЭ с нулевым сальдс платежнсго баланса п мевой инфляциєй (наибогее простые, и еющие очевидғый «геомєтрический смысл», отражены на рис.і). Их бесконечное множество, спределяготся они коюгретным значением, как прав,ило (для удоб гি,) ОПСЭ, автоматически строго определь ошем все остальные МЭП (также строго определяемым любым другим основным МЭП). Например: пусть государственными органами утверждены следующие нормы Го ударственных рахходов и инвестиций: $s=g=1 / 4$ (т. е. нормы государственных расходов и инвегтиций равны $25 \%$ ), следовательно $\psi=2$. Кроме того, их общестенные эффективнссти равны также $25 \%$, . е: $R=S=25 \%$. Идеальное налоговое бремя $\theta=1 /(2 \psi-1)=0,33$ (33\%). Норма потребления $c=1-1 / \psi=0,5$ (50\%). Темп экономическгго роста (идеальный, максимально возможный для этой совокупности

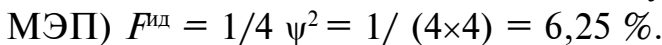

Поэтлму иерархический ряд будет в этом случае выглядеть так:

$$
c>\theta>s=g=R=S=\sqrt{ } F>F>i=0,
$$

где $c=C / Y-$ норма потребления; $Y-$ планируемая (прогнозируемая) госорганами величина ВВП (валового внутреннего продукта); $C$ - потребление; $\theta=T / Y-$ средняя налоговая нагрузка (налоговое бремя); $T$ - сумма налоговых поступлений в прогнозируемом государственными органами бюджете; $s=I / Y-$ норма инвестирования; $I-$ инвестиции; $g=G / Y-$ норма государственных расходов; $G$ - государственные расходы; $\psi=1 /(s+g)>1-$ обобщенный показатель структурной эффективности (ОПСЭ); $F=\Delta Y / Y-$ темп экономического роста сбалансированной открытой экономики, равный отношению численного значения утвержденного госорганами в бюджете или прогнозе прироста ВВП к прогнозируемому ВВП; $R=\Delta Y / I=F / s-$ показатель общественной эффективности инвестиций, равный отношению численного значения утвержденного в 
бюджете или прогнозируемого госорганами прироста ВВП к утвержденной величине инвестиций; $S=\Delta Y / G=F / g$ - показатель общественной эффективности государственных расходов, равный отношению численного значения утвержденного госорганами в бюджете или прогнозе прироста ВВП к аналогичной утвержденной величине государственных расходов; $r$ - ставка ссудного процента Центробанка страны; $\Omega=1-\left(\psi^{\text {гос }}+F^{\text {roc }}\right) /\left(\psi^{\text {ид }}+F^{\text {ид }}\right)-$ показатель эффективности и качества макроэкономической политики государства, при этом: $\psi^{\text {гос }}=1 /\left(s^{\text {roc }}+g^{\text {roc }}\right)-$ ОПСЭ ВВП (бюджета); $s^{\text {гос }}$ и $g^{\text {гос }}-$ нормы инвестирования и государственных расходов в утвержденном прогнозе; $F^{\text {ос }}$ - темп экономического роста, предусмотренный прогнозом региона; $\psi^{\text {ид }}=1 / 2 \sqrt{ } F^{\text {ос }}-$ значение ОПСЭ при утвержденном государственными органами теміле экономического роста; $F^{\text {ил }}=1 / 4\left(s^{\text {гос }}+g^{\text {гос }}\right)^{2}-$ максимальное значение темпа эконо'мического роста, достижимое при утвержденных (прогнозируемых) нормах государственных расходов и инвестиций; $i-$ инфлягция.

2. Реальные ИР СОЭ, определяемые конкретно заданными государств'нными органами численными величинами темпа экономического роста, государственных расходов (их нормой) и соотношен'яями («пересга ками») между основным' МЭП и фундаме тальной величиной: к'лрнем квадратным из темпа экономического роста. Приведем, например, два экстремальных случая

- «Общество эфґјективного г отре лления экономическая идиллия»:

$$
c>S>s>\sqrt{ } F>R>\theta>g>F>i \text {. }
$$

Обращае норма потгебления пру значительных общественной эффективност государственньіх расходо'з и норме инвестирования, магых норм налогового бремени и государствечных расхгдоов, весьма удовлетворительной обществ нной эффе итм ности инвестиций.

-- «Войны, пе иодь сложных крупиых социально-экономичеєих реформ (упрәвляемых)»:

$$
\theta>g>R>\sqrt{ } F>s>S>c>F>i \text {. }
$$

В этом ряду очевидны ғысокие нормы налогового бремени и госуцарственных расходов, незначительная ногма потребления и общественной эффектив'ности государственных расходов. Норма готребления для этих двух случаев «дрейфовал`» от максимальной к минимально возмож! яой («биологического прожиточного минимума»).

Не представляет трудностей скомбинировать другие прсмежуточные равновесные иерархические рлды (число их ограничено соответствующими перестановками).

\section{II. Неравтовесные ИР СОЭ (с заведомым нарушением иерархии МЭП)}

Как от мечалось, нб ау овесность (несбалансирозанность) макро кономической сгістемы является следствием нарушения основных требований иерархичности отногений мехду МЭП в СОЭ, несбалансировєнности финансовых инте осов государства 'и налогоілательщиков, пезвычайных об тоятельств (например, войн, некомпетентнох действий правительства), а также безусговной причиной инфляции. Например, заведомо несбалансир ва мой при заданнэм соответствующими I сорганами темге экономического роста является следуюццая часто встречающаяся экономическая система (нарушенный херархический ряд МЭП):

$$
c>g>\theta>\sqrt{ } F>s>R>S>i>F>0 .
$$

В этом ряду норма государственных расходов с весьма низкой их общественной эффективностьл больше нормы налогового бремени (заведомое перенапряжение экономическогг потенциала), а норма инвестиций и их общественная эффективность одновременно меньше корня квадратного из темпа экон ммического роста, что свидетельствует о недопустимо низкой эффективности инвесгиционной политики (государственной инвестиционной программы) и, что интересно, заведомо завышенном (возможно, в пропагандистских целях перед очередными выборами) утвержденном госорганами темпе экономического роста, численно меньшем уровня инфляции [12, с. 68].

Примером катастрофического состояния макроэкономической системы является следующий иерархический ряд МЭП:

$$
i>g>\sqrt{ } F>\theta>s>R>S>c>0>F,
$$

с чрезвычайно высокой инфляцией (гиперинфляцией) и низкой нормой потребления, неудовлетворительной собираемостью налогов и отрицательным темпом экономического роста («проеданием запасов»). 


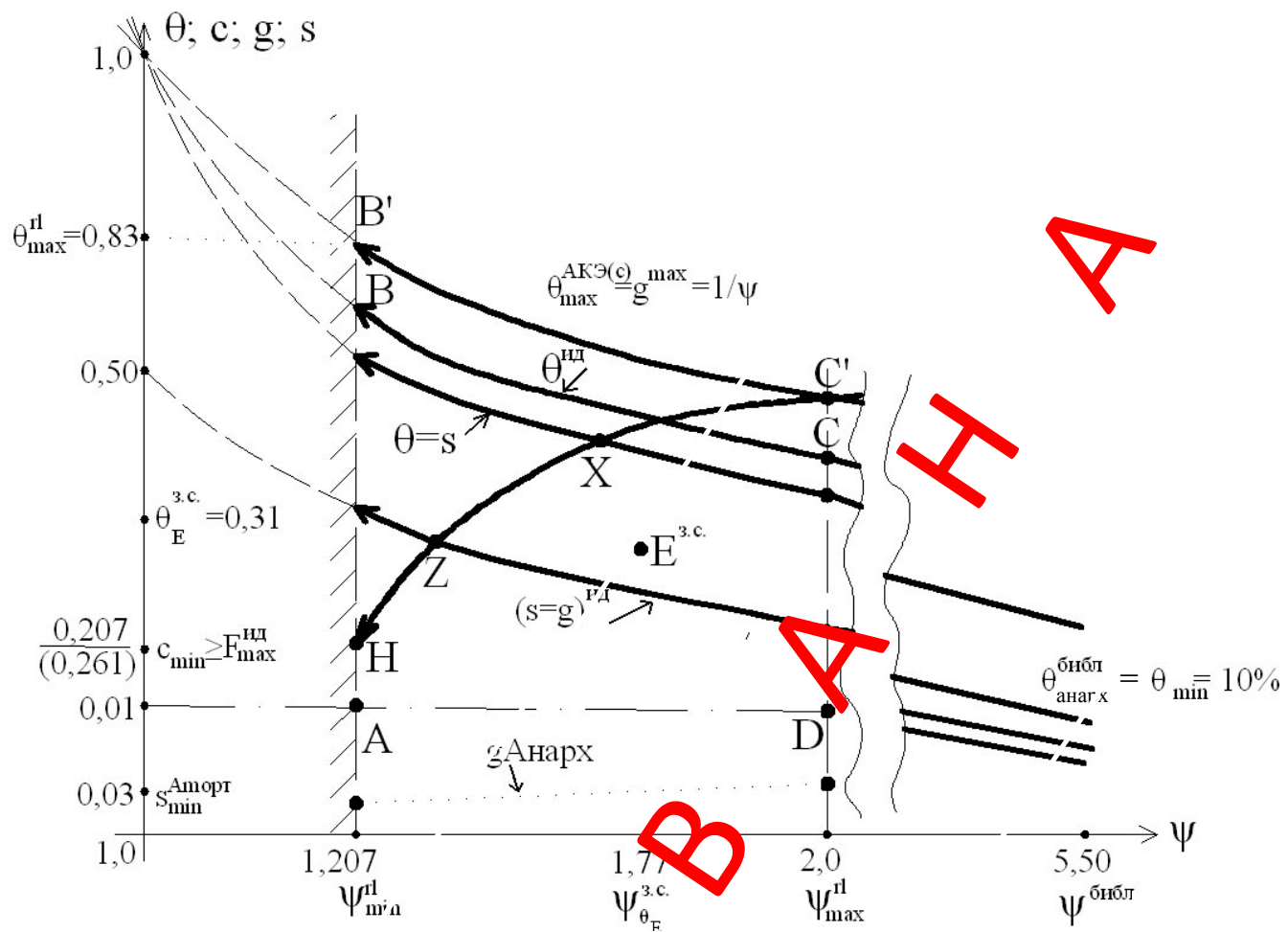

Рис. 2. Графическое 'лтображение «поля множества значений налогового бремени» и основных напрарлений (парам гр )в) налоговой макроэгономической политики Заштрихованы области невбзмо кных значений $\psi$, яеньших, чем $\psi_{\min }$

На рис. 2 приводигся графическое отображение возможных вариантов налоговой политики (бесконегіное множес Во ыбора «поле» практически всех теор сиче ки возможных значенуій средней налоговой нагрузки - налогового бремени).

Основно, пространство («налоговое поле») выбора численног рначения налогового бремени заключено межу четырьмя грлницами:

a) линией (отрезком) $A D$ - знамен'итым библейским требованием «десятины», что срсдни анархиз пу, т. е. наименьшему налогов му бремени в мш ально организсванной (в том числе анархически или религуозно) группе людей: $\theta_{\text {анарх }}^{\text {библ }}=0,1$;

б) кривой (отрезком) $B^{\prime} C^{\prime}$ - с соответствующей максимально возможному значению налоговой нагрузки, $\theta^{\max }=g_{s=\jmath}^{\operatorname{ma}}$. $=1 / \psi$, имевшему место в административгіо-командных экономиках (системах) - «ељиных фабриках» с господством государственной собственности (например, в СССР); или $B C-$ кривой идеальной спедней налоговой нагрузки $\theta^{\text {ид }}=1 /(2 \psi-1)$; в) прямой (отрезком $A B$ ), параллельной оси $\theta$, эпределяющей минимально возможное значение обобщенного показателя структурной эффективности СОЭ, равное $\psi_{\min }=1,207$ [1];

г) прямой (отрезком $D C$ ), параллельной sси $\theta$, определяющей максимально возможное значение обобщенного показателя структурной эффективности СОЭ в реальных, исторически и статистически подтвержденных границах, равное $\psi_{\max }^{\text {реал }}=2$.

Очевидны два характерных (экстремальных, геометрических) направления макроэкономической политики («налоговый крест»):

- по прямой из точки $A\left[\psi_{\min }=1,207 ; \theta_{\text {анарх }}^{\text {библ }}=0,10\right]$ в точку $C^{\prime}\left[\psi_{\text {макс }}^{\text {реал }}=2 ; \theta^{\text {max }}\right]$, что эквивалентно переходу от «от анархической к административно-командной экономике $\mathrm{AK} Э(\mathrm{C}) »$;

- по прямой из точки $B^{\prime}\left[\psi_{\min }=1,207 ; 1 / \psi_{\min }=1,207\right]$ в точку $D\left[\psi_{\text {макс }}^{\text {реал }}=2 ; \theta_{\text {анарх }}^{\text {библ }}=0,1\right]$, что эКвивалентно переходу «от суперАКЭ(С) к архианархической экономике». 
Легко высчитываемая точка $E$ пересечения этих направлений определяет, по нашему мнению, «золотосерединное» значение средней налоговой нагрузки в «усредненной экономике», $\theta_{E}^{3 c}=0,31$ (весьма близкое к показателю среднего налогового бремени в США и Японии - около $30 \%$ ), при $\psi_{E}^{3 \mathrm{c}}=1,77$ (также очень близком к японскому, 1,81), в свою очередь, определяющее «ядро» налоговой политики и его исторический «дрейф».

Интересными являются также три характерные «тройственные» точки налогового поля, расположенные на кривой нормы пютребления $\mathrm{HC}^{\prime}=1-1 / \psi$, в которых одновременно соблюдается равенство трех ('и более) разных МЭП:

a) точка $X$, пересечения кривыу нормы потребления и кривой равенства ғормы налогового бремени и инвестиций, в которой $c=\theta=s$

б) точка $C^{\prime}$, пересечения кривых нормы потребления и кривой равенства максимальных значений средней налоговой нагру и и государственных расходо's в АКЭ(С), в КбТ рой $c=\theta=g$;

в) точка $Z$, пересечения кривых нормы потребления и кривлй равенства_максимальных значений гогударственнь ра ходов и инвестиций и их общественных эффективностей: $c=g=s=R=S-$ идеальная цель идеальной макроэкономической стратегии, «магистральная траектория» любого развитого государ ства (реальн -ушествующий вари ант - «Шіведский социализм»).

На рис. 2 приведена высчитанная нами на ссновании [1] «анархистская» кривая нормы государ енных расходов, минималльное значе чие оторой равно $1,9 \%$, а максимальное 1\%. Мировая етатистика настаивает на минимальной норме инвестирования, не меньшей средней нормы амортизационных отчислений, $s_{r \text { ain }}^{\text {ar.ort }}=3 \%$ (cм. рис. 2). Приведено также максимально возможное значение среднег̆ нормы налоговой нагрузки, $\theta_{\max }^{r l}=0,83$, которое делает понятным близкое к нему значение налогового бремени в Швециг. Для более подробного анализа вариантов, налоговой политики (выгвления и обосғования соотношений между оснсвными МЕП) приведены также из рис. 1 кривая идеальной нормы налогового бремени $\theta^{\text {ид }}=1 /(2 \psi-1)$ и кривая идеальных значений норм государственных расходов и инвестиций $(s=g=R=S)^{\text {ид }}=1 / 2 \psi$.

Безусл'љвн, разме малк и структура сальдо платежного балан страны оказывагот сильно влияние на качество макроэконгмическсго состояния. Например, положительное сальдо соответс вующей экономики. безуслгвно, в денежн лм (количественнсм) отношении повышае ее эффективность. И наоборот, отрицательное сальдо платежного баланса снижает качество макроэкономической политики. При этом особое значегяие приобретает товарна́ Т яктура экспорта и импорта. Очевидна н перспективность, преобладания в структуре экспорта ограгіиченных природных ресурсов в обмен на продовольствие и невыокотехнологичную 'заведомо отсталую от герд дового мировог' уровня) продукцию.

Bыводы. Рассмотренная модель экономики (несмотря на ее кажущуюся парадоксальность) имела место в период 1879-1897 гг. в реальной экономике США («Золотая эпоха» золотого :тандарта, введенного в 1879 г.). В результате США вышли на первое место в мире пл объему ВВП и промышленного производства, на лидирующие позиции в мировой экономике [13, с. 30]. Модель хорошо отрг.жает известные периоды парадоксальных ззлетов экономических систем в СССР, Германии, Японии, Южной Корее, Китае.

Несомненно, данная модель, ее основные ограничения, не может быть полностью адекватна реальности, поскольку речь идет о человеческой деятельности, развивающейся в необратимом времени, несводимости общественного прогресса, развития человека к увеличению денежных доходов или к приумножению материального богатства, темпов экономического роста. Несовершенство людей и их отношений делает значимым фактор случайности, неопределенности.

Аналитические методы, назначением которых должно служить преодоление субъективизма в принятии решений, на деле нередко используются в качестве одного из инструментов политической борьбы. Это может служить предостережением экономстам, которые обязаны быть блюстителями общественной дальновидности в экономических вопросах. 


\section{СПИСОК ЛИТЕРАТУРЫ}

1. Краткая философская энциклопедия. М.: Энциклопедия, 1994. 576 с.

2. Овсиенко Ю.В. и др. Устойчивое развитие: концепция и стратегические ориентиры// Экономика и математические методы, 2007. Т. 43. № 4. С. $57-71$.

3. Губанов С. Рост без развития и его пределы // Экономист. 2006. № 4. С. 5-19.

4. Самуэльсон П. Экономика. Вводный курс. М.: Экономика, 1964 (оригинал: Economics, 1948). $843 \mathrm{c}$.

5. Блауг М. Методология экономической науки, или как экономисты объясняют / пер. с англ. // Вопросы экономики. 2004. С. 30-41.

6. Владимиров С.А. О моделировании сбалансированной экономики // Общество и экономик'. 2010. № 6. С. 31-48.

7. Владимиров С.А. Методология оцену.и и анализа экономической эффективности иғвестиционных проектов в строительстве : автогеф. дис. ... д-ра экон. наук. СПб.: СПбГИЭУ, $200^{\prime} \%$.

8. Владимиров С.А. О некоторых пгичинах несбалансированности экономических систем и направлениях налоговой политики // Налоги. 2010. № 2. С. 34-42.

9. Владимиров С.А. Определєние минимальной общественной эффективност.и инвестищионно-

\section{RE'ERENCES}

1. Short philosoph.ıcal entsiklopedija. Moscow, Encyclopedia, 1994. (rus)

2. Ovsienko J.V. et al. the Sustainable development: the concept and strawsic reference points. Economy and mathematical methods, 2007, vol. 43, no. 4. (rus)

3. Gubarov S. Rost wit hout development and its limits. The Economist, 2006, no 4. (rus)

4. S‘myelson P. Ekonomiká. Introduction kurs. th.: ecrnomy, 1964 (the original: Economics, 1948). (rus)

5. Blaug M. Mandologija of an economic science or as economist exp in. The lane witn English. Magazine economy nolions, 2004. (rus)

6. Vladimirov S.A. On the modelins, of a balanced economy. Society and Economy, 2010, no. 6, pp. 3148. (rus)

7. Vladimirov S.A. The methedology of evaluation and cost-benefit analysis of ir.rvestment projects in building : dissertation author's abstract on scientific degree of Doctor of Fconomic Sciences. St. Petersburg State Engineering and Economic University. St. Petersburs, 2007. (rus) строительных проектлв - один из главных способов борьбы с коррупцией // История государства и права. 2002. № '́,

10. Владимигов С.А. О безупречном внеидеологическом критерии (индикаторе) макроэкономической эффек.гивности государственного бюджета (ВВП) // Финансы и щuт, 2006. № 18(222). C. $54-60$

11. Зладимиров С.А. О Оущности и оснозных напразлениях регулирования сбалансированғости и эффективности макроэкономических состьяний // Журнал экономичо хой теории. 2010. №‥ С. 9.

12. Владими С.А. Модель сбагансированной макроэкономшеской системы // Проблемы теории и практики управления. 2014. № 5. С. $126-134$.

13. Владимиров С.А. О пок'зателе эффективности и ве жғций // Финансь.. 2002. № 6. С. 73.

14. Ф рд Г. Моя жизнь. мои достижения. М.: Госиздат, 1924. 223 с.

15. Экономико-математический энциклопедический словарь / п'лд ред. В.И. Даниловаильяна. М.: Инфра-М, 2003. 688 с.

16. Иноземцев В.Л. «Постамериканский мир»: мечта дилетантов и непростая реальность // Мировая экономикд и международные отношения. 2008. № 5. С. 2'l-36.
8. Vladimirov S.A. Some reasons for the imbalance of economic systems and the directions of tax policy. Taxes magazine, 2010, no. 2, pp. 34-42. (r'as)

9. Vladimirov S.A. Determination of the minimum social efficiency of investment and construction projects - one of the main ways of combating corruption. History of State and Law, 2002, no. 6. (rus)

10. Vladimirov S.A. About impeccably nonideological criteria (indicators) macroeconomic efficiency STATE BUDGET (GDP). Finance and Credit, 2006, no. 4, no. 18(222), pp. 54-60. (rus)

11. Vladimirov S.A. About primary causes of neravnovesnosti of economic systems and directions of tax policy. The Journal of Economic Theory, 2010, no. 1, p. 9. (rus)

12. Vladimirov S.A. The Model of a Balanced Macroeconomic System. Theoretical and Practical Aspects of Management, 2014, no. 5, pp. 126-134. (rus)

13. Vladimirov S.A. On the performance of investments. Finance, 2002, no. 6, p. 73. (rus)

14. Ford G. My life, my achievements. Moscow, The State publishing house, 1924. (rus) 
15. The Economic-mathematical encyclopedic dictionary. Under the editorship of V.I. DanilovaDaniljana. Moscow, Infra TH, 2003. (rus)
16. Inozemtcev V.i. Foreigners of Century $\Omega$ «the Postamerican world»: dream of laymans and an uneasy reality. Economic and the ir.ternational relations, 2008, № 5. (rus)

ВЛАДИМИРОВ Сергей Арсеньевич - профессор кафедры Санкт-Петербургского государственного университета аэрокосмического приборостроения, доктор эконољических наук.

190000, ул. Большая Морская, д. 61, Санкт-Петербург, Россия. E-mail: idea 10 mail.ru

VLADIMIROV Sergei A. - Saint-Petersburg State Universitv of Aerospace Instrum sntation.

190000. Bolshaya Morskaya str. 61, St. Petersburg, Russia. ¿̇-mail: ideal_ideal@mail.ru
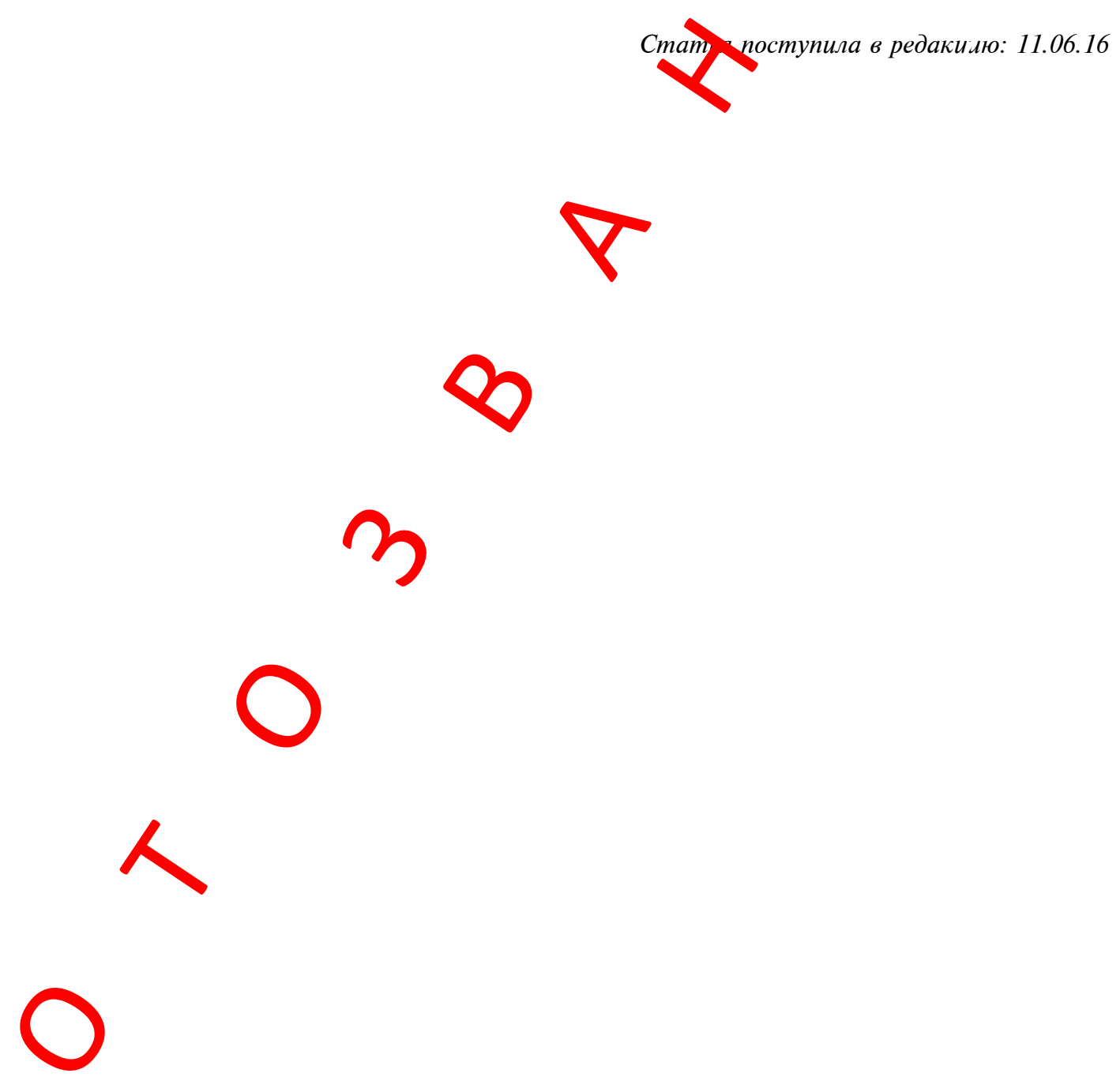

(C) Санкт-Петербургский политехнический университет Петра Великого, 2016 